Several articles in this Journal have discussed this question without settling it. The results of Williams and Phythian ${ }^{1}$ can differ from those of Lambert ${ }^{2}$ (as given by Hiraiwa $^{3}$ ) by $2 \mathrm{~km}$. None of the articles mentioned the formulas given by Sodano, ${ }^{4}$ Rainsford, ${ }^{5}$ and Vincenty. ${ }^{6}$ The latter two claim accuracy to about a millimetre over distances of $19000+\mathrm{km}$. Take one example from Hiraiwa: two points, both at $60^{\circ}$ geodetic latitude, are separated by $100^{\circ}$ of longitude. Hiraiwa uses Lambert's formula to get a distance on the Bessel spheroid of 2709.27 geographical miles; Williams and Phythian say $2708 \cdot 12$. Lambert's alternative formula, using reduced latitudes, gives $2709 \cdot 2861$. Sodano's standard formula gives $2709^{\cdot 286} 26$; his higher-precision formula and Rainsford's and Vincenty's formulas all give $2709^{\cdot 286} 35^{6}$.

The special case of equator-to-equator arcs (discussed by Williams and $\mathrm{Phythian}^{7}$ ) greatly simplifies Rainsford's and Vincenty's formulas for the quantity $(\lambda-L)$, enabling us quickly to find the half-period of a geodesic with any given vertex latitude. Any of the formulas will then calculate the length of the equator-to-vertex arc, which we then double. It turns out that the geodesic (on the Bessel spheroid) with vertex at $45^{\circ}$ geocentric latitude measures $1077^{\circ} .96$ geographical miles and $179^{\circ} 34^{\circ} 5^{26^{\prime}}$ of longitude between each crossing of the equator.

\title{
REFERENCES
}

1 Williams, R. and Phythian, J. E. (1989). Navigating along geodesic paths on the surface of a spheroid. This Journal, 42, 129.

${ }_{2}^{2}$ Lambert, W. D. (1942). The distance between two widely separated points on the surface of the Earth. Journal of the Washington Academy of Sciences, 32, 125.

${ }^{3}$ Hiraiwa, T. (1987). Proposal on the modification of sailing calculations. This Journal, $4^{\circ}$, 138.

${ }^{4}$ Sodano, E. M. (1965). General non-iterative solution of the inverse and direct geodetic problems. Bulletin Geodesique, 75.

${ }^{5}$ Rainsford, H. F. (1955). Long geodesics on the ellipsoid. Bulletin Geodesique, 37, 12.

${ }^{6}$ Vincenty, T. (1975, 1976). Direct and inverse solutions of geodesics on the ellipsoid with application of nested equations. Survey Review, 22, 176, 88; additional formulas, 23, 180, 294.

7 Williams, R. and Phythian, J. E. (1992). The shortest distance between two nearly antipodean points on the surface of a spheroid. This Journal, 45, I 14.

See also:

Bowring, B. R. (1983). The geodesic inverse problem. Bulletin Geodesique, 57, 109 (Correction, $58,543)$.

Meade, B. K. (1981). Comments on formulas for the solution of direct and inverse problems on reference ellipsoids using pocket calculators. Surveying and Mapping, 4I, I (March), 35.

KEY WORD

I. Geodesy.

\section{The Adventures of Leonard}

\author{
J. B. Parker
}

This article, though light-hearted, has a serious purpose, which is to attempt to act as an aperitif to the many distinguished articles about the Kalman filter, some of which are referred to in the text. Such articles have appeared both in the Journal and in Navigation News. 
Leonard, a leviathan, is a creature whose physiognomy is extremely well adapted to his needs and purposes. The latter include the ability to travel, possibly at enormous speeds, through different types of environment with a view to arriving, often with incredibly high precision and timing, at a preordained destination, doing his job there, and then, hopefully, being able to navigate back to his wife and family at base. Leonard is a very conscientious and painstaking creature, although, because his anatomy is so sophisticated, he may have very little actual decision-making to carry out on his travels.

Leonard, like every other creature, requires food. There is plenty of it around (plankton), though the cells are small in relation to Leonard's enormous size. So all the time he swims with his mouth wide open, letting the plankton (which might come in a number of different shapes and sizes) just drift in. On the whole, his digestive system copes admirably. In particular, once digested, the remains of the food need no longer be stored in Leonard's belly, vast though this is.

Equipped with such a powerful physiognomy and with a chassis as tough as old boots, what has Leonard to fear? Quite a lot, as he is the first to recognize. The structure of his digestive system depends on very careful and diligent experimentation ${ }^{1}$ to determine what are known as his 'variance-covariance' coefficients, a procedure known as 'modelling', and because these have to be determined pretty accurately it is just as well that Leonard is always given a thorough-going medical before he sets off. The possible dangers of this procedure are well known to Leonard; he sometimes modifies the original 'expert' modelling parameters in the light of his own onboard operational experience ${ }^{2}$. Leonard is a very intelligent, self-adaptive, leviathan.

For what is the food used? In Leonard's Dad's days, when there was very little of it around, the answer was simple: determination of position. Nowadays this is not generally sufficient, for it may be vital to determine much more information - for example, on velocity and trim. Here, it is relevant to tell a sad story of Leonard's youth. Frightfully keen, he was able to reach his target with a radial error quite insignificant when viewed against his enormous dimensions. His ETA was out by only 6 milliseconds ( $1 \cdot 2$ standard deviations). Alas, when he got to his destination, he was upside down. The chaps back at base pulled his fin unmercifully but his seniors took a very dim view, expressing doubts as to whether Leonard had the right attitude for this sort of work. There followed a short period of hospitalization, during which two or three more rows and columns (yaw, pitch, roll) were added to his then fairly modest anatomy. Since then, Leonard has always been the right way up. All this information is embodied in what Leonard calls his "state vector' ${ }^{3}$ and the whole purpose of the intake of plankton (new information) is to enable him to estimate it, his anatomy consisting of a set of interlocked linear equations ${ }^{1}$ connecting the food to the state vector.

In ideal circumstances, all this works swimmingly but the real world may cause problems. On one mission, for example, Leonard got embroiled with Lolita, a nubile, albeit enormous, leviathaness and his resulting non-linear behaviour played havoc with his digestive system. During this encounter, which he survived without losing either his honour or his sense of purpose, both whales of course continued to have their mouths wide open, accumulating the necessary plankton. Similar troubles beset Leonard when he had to take evasive action in order to avoid the attentions of a group of harpoonists. But, in situations like this, Leonard is able to do a very clever thing. Though his anatomy is optimum in the sense that the best possible balance between past experience and current data is struck, he might intervene, using his tuning fork ${ }^{3}$ to give less weight to past experience (obtained during a tricky epoch) and more to knowledge based on later data when the period of hassle is over. Conversely, if he suspects his recent data, the plankton not being to his taste, he may do the reverse. 
Indeed, the integrity of the plankton is often a matter of concern to Leonard. One thing that may happen is that the great majority of the food approaches him from more or less the same direction. Leonard's digestive system does not like this and the poor creature goes 'out of condition' as a result. Dad had similar problems in the old days, when the only two position lines he could get intersected at an unsatisfactorily narrow angle. But palliatives are at hand, for Leonard has learned a bit about Ridge Regression ${ }^{4}$. Another serious problem is that some of the plankton may be gritty, if not grotty; a good leviathan would not want any truck with this sort of food. So the incoming amoebae are put through a sort of sifting process, called variously 'screening', 'smoothing', or even 'data adjustment'. Also, he may just decide to ignore suspicious food. But Leonard, though completely confident about the validity of such procedures, is very shy and extremely reluctant to talk about them.

The thought occurs to some of Leonard's friends that, however careful the modelling carried out for a particular whale (or else for a subset of whales) may be, the results may not necessarily be valid for the population of leviathans at large. ${ }^{5}$ Thus Lolita, for one, is equipped with several non-linear facilities that our honest, if strait-laced, Leonard would be much too bashful to recognize. Dad had a similar problem at his navigation school during World War II, finding it was no good just swinging the compass on one or two aircraft and calling it a day; each one had to be dealt with individually.

Leonard's son is rather an awkward brat with a tendency to challenge some of Dad's views. Perhaps with his tongue in his cheek, Ludovic even goes so far as to snipe at what he calls 'Dad's sacred cows', citing not only the difficulties of the modelling concept but also Dad's preoccupation with optimum procedures, on the grounds that the real world is far from being an optimal world. In his wilder moments he even queries the sanctity of the least squares principle. If Ludovic gets his $\mathrm{PhD}$, he is thinking about setting pen to paper about all this. Leonard is aghast but puts it all down to growing pains. His wife, Leonora, is pig in the middle, but has strong views about the need to make the operational application of her husband's ideas, as opposed to a mere description of them, available to her many friends.

Finally, a sad story about Leonard's cousin Lothario, now in the doghouse after a disgraceful incident involving Lolita. Lacking his relative's moral rectitude, Lothario's contact with Lolita caused an enormous tidal wave (Lolita weights seven and a half tons) resulting in environmental damage running to millions of pounds. Lothario's mission was abortive and a very tired, shame-faced leviathan only just managed to make it back to base. But every cloud has a silver lining and Lothario's mentors, some of whom are Operational Research specialists, accumulated some valuable, and much needed, system failure data.

Leonard, however, was not amused.

\section{REFEREN C ES}

1 Stokes, R. F. and Smith, S. G. ( $\left.\mathrm{I}^{9} 8_{3}\right)$. Integrated navigation systems for aircraft. This Journal, 36, 359 .

${ }^{2}$ Abbott, J. P. and Gent, C. R. ( $\left.198_{3}\right)$. Self-adaptive filters for the integration of navigation data. This Journal, 36, 64.

${ }^{3}$ Napier, M. (1990). Integration of satellite and inertial positioning systems. This Journal, 43, 48.

4 Kelly, R. J. (1990). GDOP, ridge regression and the Kalman filter. This Journal, 43, 409.

${ }^{5}$ Dove, M. J. and Miller, K. M. (1989). Kalman filters in navigation systems. This Journal, 42,255 . 


\title{
KEY WORDS
}

I. Kalman filters. 2. Errors. 3. Statistics.

\section{An Interesting Problem in Spherical Trigonometry}

\author{
Olay Öztan, Ufuk Özerman and Zafer Kizilsu
}

\author{
(Istanbul Technical University, Maslak, Istanbul, Turkey)
}

This paper provides an example of the versatility of mathematics and how it can be applied to the formulation of navigation methods which are more elegant and efficient than those traditionally used. For example, there is little use currently made of the calculus or the techniques of differential geometry. A difficulty in applying general mathematical methods is the inconsistency of navigation coordinate systems, which could usefully be changed so that longitude and GHA, for instance, could be measured eastwards in the range $0^{\circ}-360^{\circ}$.

The problem considered below is of little importance in itself, either in terms of mathematics or navigation, but it illustrates how alternatives to traditional approaches to navigational requirements can lead to more attractive solutions. This particular problem has been inspired by the book Theory and Problems of Differential and Integral Calculus in SI Units.'

I. PROBLEM. A ship at the point $P_{1}\left(\psi_{1}=\psi\right.$ north, $\left.\lambda_{1}=\lambda\right)$ is starting to move from north to south on the meridian $\lambda$ with a constant velocity $\nu / \cos \psi$. At the same moment another ship at point $P_{2}\left(\psi_{2}=\psi\right.$ north, $\left.\lambda_{2}=\lambda+\psi\right)$ is starting to move from east to west on parallel of latitude $\psi$ with constant velocity $\nu$. What is the minimum distance between these ships? (In order to make the problem significant, the angular velocities of the ships have been selected to be equal. Here $\lambda_{2}>\lambda_{1}$ and $0^{\circ} \leqslant \psi \leqslant 90^{\circ}$.)

2. SOLUTION. The angular velocity of the ships is,

$$
\omega=\frac{\nu \cdot \rho}{R \cdot \cos \psi} .
$$

At a time $t$, the longitude difference $\Delta \lambda$ between the coordinates of points $P_{1}^{\prime}(\psi-\omega t, \lambda)$ and $P_{2}^{\prime}(\psi, \lambda+\psi-\omega t)$ is

$$
\Delta \lambda=\psi-\omega t,
$$

(Figure 1). If we use the edge cosine theorem for the triangle $N P_{1}^{\prime} P_{2}^{\prime}$, it can be written as follows :

$$
\cos S=\sin (\psi-\omega t) \cdot \sin \psi+\cos ^{2}(\psi-\omega t) \cdot \cos \psi .
$$

The minimum value of $S$ is obtained by setting, the derivative of equation (3), equal to zero. Thus from (3), we get equation (4)

$$
\cos (\psi-\omega t) \cdot[2 \cdot \cos \psi \cdot \sin (\psi-\omega t)-\sin \psi]=0 .
$$

If the first multiplier $\cos (\psi-\omega t)$ of the equation is set equal to zero then, from equation (3) we obtain,

$$
S_{\min }=90^{\circ}-\psi \text {. }
$$

In that case a minimum of equation (3) arises when the ship is at the North Pole. Another minimum of equation (3) is obtained when the second multiplier of equation (4) is set equal to zero. Thus we obtain,

$$
\sin (\psi-\omega t)=\frac{1}{2} \tan \psi
$$

